money" families can trace the source of their fortunes to the fur trade. Corless reinforces this connection to the past in the fur portraits by using the same furs in her portraits of past and present royals: Queen Elizabeth I, Queen Elizabeth II and Prince Charles. She implies that the Elizabethan power structures of the colonial age exist to some degree to this day. And since viewers are standing on fur as they look at these images, they too become entangled in the historically complex legacy of the fur trade. Through this physical connection Corless signals the links between the blankets and the portraits, between Canada's origins and its present and between the notable achievements and inconceivable disgraces that colour this nation's evolution.

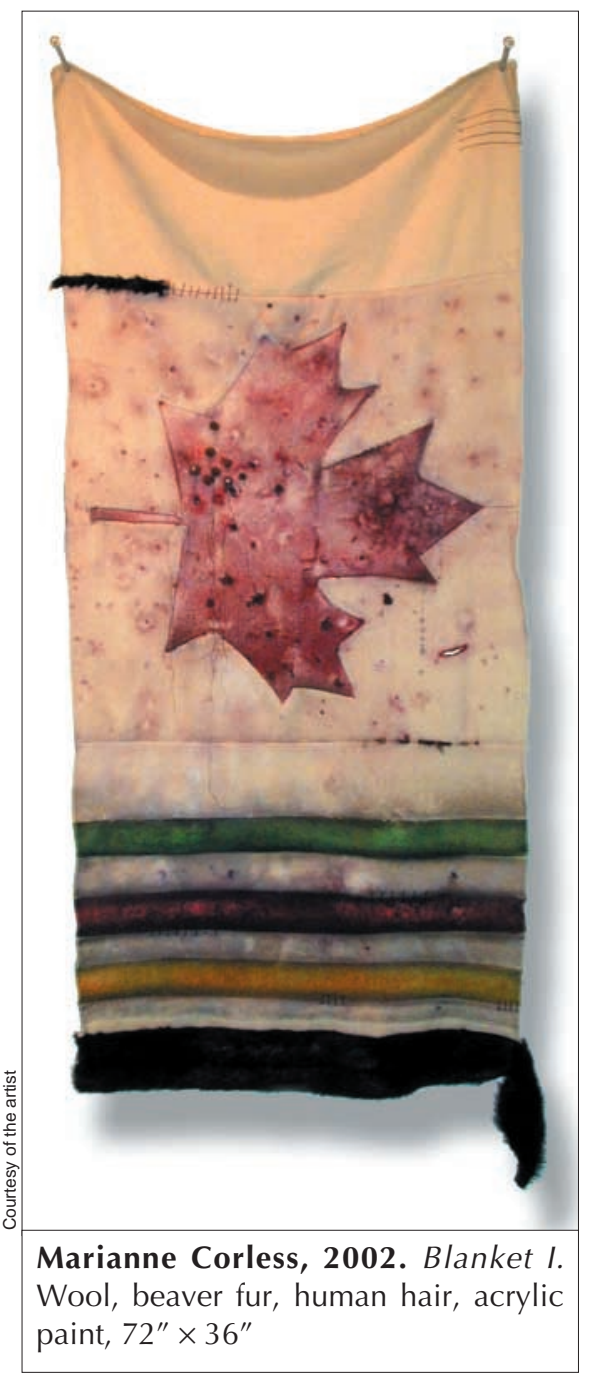

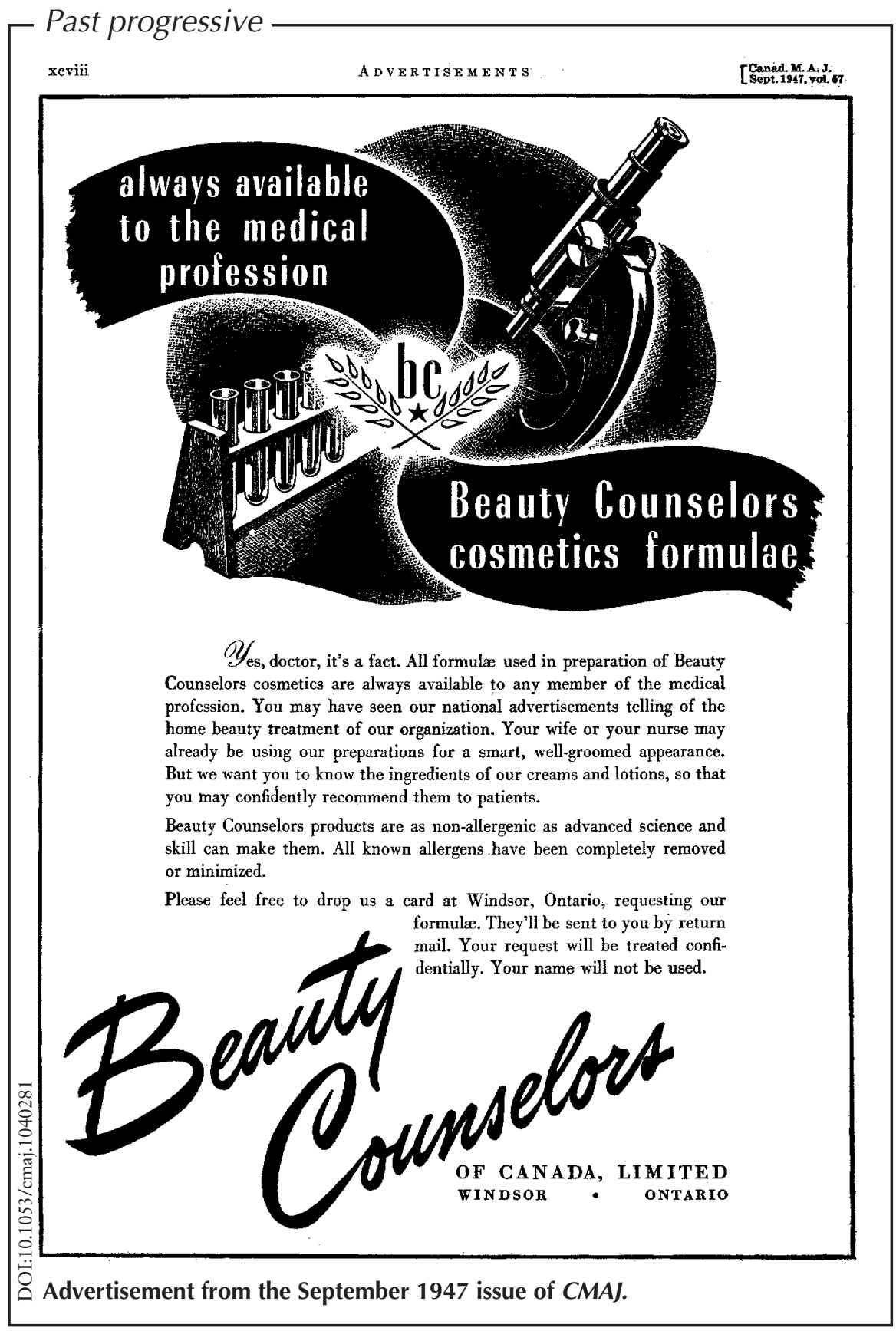

At an artist's talk held in conjunction with the exhibition, Corless spoke about her desire to connect past and present issues of Canadian identity: "In my work, I am using the Canadian flag ... [and] the jolt of ownership that it evokes to generate a sense of responsibility in the viewer. The flag belongs to all Canadians and we must accept all that it represents: greatness, vision and violence. That is who we are. That is who I am." Further is a beautiful, complex and, at times, painful meditation on how contemporary ideas of Canadian cultural and national identity are most clearly understood when they include an awareness of Canada's past.

\section{Meg Walker}

Writer and artist

Winnipeg, Man. 